\title{
Mechanical properties of dispersed ceramic nanoparticles in polymer composites for orthopedic applications
}

This article was published in the following Dove Press journal:

International Journal of Nanomedicine

9 April 2010

Number of times this article has been viewed

\section{Huinan Liu \\ Thomas J Webster}

Division of Engineering, Brown University, Providence, RI, USA
Correspondence: Thomas JWebster Division of Engineering and Department of Orthopaedics, Brown University, 182 Hope Street, Providence, RI, 02912, USA

Tel + I 4018632318

Fax + I 4018632323

Email thomas_webster@Brown.edu
Abstract: Ceramic/polymer composites have been considered as third-generation orthopedic biomaterials due to their ability to closely match properties (such as surface, chemistry, biological, and mechanical) of natural bone. It has already been shown that the addition of nanophase compared with conventional (or micron-scale) ceramics to polymers enhances bone cell functions. However, in order to fully take advantage of the promising nanometer size effects that nanoceramics can provide when added to polymers, it is critical to uniformly disperse them in a polymer matrix. This is critical since ceramic nanoparticles inherently have a strong tendency to form larger agglomerates in a polymer matrix which may compromise their properties. Therefore, in this study, model ceramic nanoparticles, specifically titania and hydroxyapatite (HA), were dispersed in a model polymer (PLGA, poly-lactic-co-glycolic acid) using high-power ultrasonic energy. The mechanical properties of the resulting PLGA composites with well-dispersed ceramic (either titania or HA) nanoparticles were investigated and compared with composites with agglomerated ceramic nanoparticles. Results demonstrated that well-dispersed ceramic nanoparticles (titania or HA) in PLGA improved mechanical properties compared with agglomerated ceramic nanoparticles even though the weight percentage of the ceramics was the same. Specifically, well-dispersed nanoceramics in PLGA enhanced the tensile modulus, tensile strength at yield, ultimate tensile strength, and compressive modulus compared with the more agglomerated nanoceramics in PLGA. In summary, supplemented by previous studies that demonstrated greater osteoblast (bone-forming cell) functions on well-dispersed nanophase ceramics in polymers, the present study demonstrated that the combination of PLGA with well-dispersed nanoceramics enhanced mechanical properties necessary for load-bearing orthopedic/dental applications.

Keywords: nanocomposites, ceramic nanoparticles, titania nanoparticles, hydroxyapatite nanoparticles, dispersion, agglomeration, biodegradable polymer, PLGA, mechanical properties, orthopedic/dental applications

\section{Introduction}

Ceramic/polymer composites have been considered as third-generation orthopedic biomaterials due to their ability to closely match properties of natural bone compared with first generation (metals or metal alloys) and second (ceramics) generation bone substitute materials. ${ }^{1}$ Ceramic/polymer composites offer a promising approach to combine the advantages of bioactive, mechanically strong ceramics with biodegradable, flexible polymers to optimize physicochemical, mechanical, and biological properties of synthetic bone substitutes. In the past few years, the development of ceramic/polymer composites as orthopedic materials has attracted more and more attention. ${ }^{2-4}$ Specifically, from the biological perspective, osteoblast (bone-forming cell) functions have been 
improved on ceramic/polymer composites due to the greater osteoconductivity properties offered by the bioactive ceramic phase. ${ }^{5-9}$ From the point-of-view of physicochemical properties, ceramic particles (such as titania or hydroxyapatite, HA) in a biodegradable polymer (such as poly-lactic-co-glycolic acid, PLGA) can provide a $\mathrm{pH}$ buffering effect to the polymer to tailor the degradation and resorption kinetics of the composite, thus, preventing acceleration of polymer degradation, avoiding the formation of an unfavorable acidic environment detrimental for cells, and reducing side-effects (such as inflammation) from the acidic degradation by-products of polymers. ${ }^{10,11}$ Thus, due to their smaller size which may further exaggerate the benefits of adding ceramics to polymers, nanophase ceramic polymer composites have a strong potential for improving current orthopedic/dental prostheses.

It is, therefore, intriguing and necessary to examine the mechanical properties of these novel nanocomposites for orthopedic applications. This is because a mismatch in the mechanical properties of metallic implants and physiological bone may result in stress-shielding problems leading to implant loosening and failure. ${ }^{12}$ Metallic materials widely used in orthopedic applications have much stronger mechanical properties (such as elastic modulus) than natural bone, which can weaken the newly formed bone interface due to stress-shielding. Because natural bone is under continuous physiological stresses (such as compression, tension, torsion, and/or bending), the mechanical properties of orthopedic/ dental materials should closely match those of living bone. This is necessary to minimize stress and strain imbalances during physiological loading conditions, which will lead to implant failure. In terms of the aforementioned ceramic/ polymer composites, the stiffer ceramic phase is important for improving mechanical properties of materials used for load-bearing applications. ${ }^{12-15}$ Specifically, Thomson et al demonstrated that the compressive yield strength increased from $0.95 \pm 0.11 \mathrm{MPa}$ for PLGA foams to $2.82 \pm 0.63 \mathrm{MPa}$ for foams when HA fibers were added at weight ratios of 7:6 (PLGA:HA). ${ }^{4}$ Wei et al demonstrated that the compressive modulus of HA/PLA scaffolds increased with HA content. ${ }^{16}$ Specifically, the modulus increased from 4.3 MPa for plain poly(lactide) (PLA) scaffolds to $8.3 \mathrm{MPa}$ when the weight ratio of HA to PLA was 50:50. ${ }^{16}$

More importantly, ceramic/polymer composites can be further formulated to mimic many aspects of natural bone by utilizing nanoparticles as the ceramic phase. This is because natural bone is a nanostructured composite composed of a polymer matrix (mainly collagen) reinforced with nanometer-sized ceramic particles (mainly carbonated HA). ${ }^{12}$
Ceramic/polymer nanocomposites may be synthesized to possess hardness, bending, compressive, and tensile strengths that are higher than conventional ceramic composites but are more similar to physiological bone. Mechanical deformation theory indicates that as grain size is reduced, high-volume fractions of interfacial regions compared with bulk leads to increased deformation by grain-boundary sliding and short-range diffusion-healing events, thus, increased ductility in nanocrystalline ceramics may be observed. ${ }^{17,18}$ Indeed, greater mechanical properties have been reported for polymer composites with a reduction in ceramic grain size into the nanometer range. ${ }^{19}$ For example, McManus et al reported that the bending moduli of composites of PLA with 40 and $50 \mathrm{wt} \%$ nanophase $(<100 \mathrm{~nm})$ alumina, titania and HA were significantly greater than respective composite formulations with conventional coarser grained ceramics. ${ }^{19}$ Specifically, compared with a bending modulus of $60 \pm 3 \mathrm{MPa}$ for plain PLA and $870 \pm 30 \mathrm{MPa}$ for conventional titania/PLA composites with a weight ratio of 50/50, the bending modulus of nanophase titania/PLA composites with a weight ratio of 50/50 was $1960 \pm 250 \mathrm{MPa} .{ }^{19}$ In the paper, ${ }^{19}$ the ceramic nanoparticles of varying amounts $(30,40$, and $50 \mathrm{wt} \%)$ were simply mixed with the polymers in organic solvents to compare the effect of the weight percentage of particles on the mechanical properties of the composites. The dispersion status of the nanoparticles was, however, not addressed. Nanoparticles tend to agglomerate and such agglomeration significantly influences the properties of nanocomposites. Therefore, the weight percentage of nanoparticles was kept constant in the present study in order to reveal how the dispersion status of nanoparticles in a polymer matrix influences the mechanical properties of nanocomposites.

In addition, superior cytocompatibility and biodegradation properties of ceramic/polymer nanocomposites over conventional composites have been reported pertinent for orthopedic applications. ${ }^{8,10}$ Specifically, previous studies demonstrated that well-dispersed nanoparticulate titania in PLGA composites promoted osteoblast adhesion and longterm functions (such as collagen synthesis and calciumcontaining mineral deposition) compared with pure PLGA and more agglomerated titania in PLGA composites. ${ }^{8}$ The controlled dispersion of titania nanoparticles in PLGA also further decreased the weight loss of the bone scaffolds, reduced the harmful acidic $\mathrm{pH}$ changes during PLGA degradation, and prolonged the mechanical integrity of the scaffolds. ${ }^{10}$ Due to the ability to tailor such degradation rates, these nanocomposites are also good candidates for controlled drug delivery applications. ${ }^{20}$ 
The objective of the present study was to investigate the mechanical properties of polymer composites with welldispersed or agglomerated nanophase ceramics (titania or HA) while keeping the percentage of nanophase ceramics constant. The research question was whether the mechanical properties of nanocomposites could be tailored by controlling the dispersion of nanoparticles alone. A biodegradable polyester, PLGA, was chosen as a model polymer matrix since it has been widely studied for biomedical applications and has been approved by the FDA for certain clinical applications. Nanophase titania and HA were chosen as the model ceramics due to their wide acceptance and use in orthopedics and due to their excellent biocompatibility properties for promoting bone cell functions. ${ }^{8,9}$ The dispersion of nanotitania or nano-HA in PLGA was controlled by sonication and was characterized by field emission scanning electron microscopy (FESEM) and image analysis techniques. For this purpose, two major stresses (compression and tension) that natural bone experiences under physiological loading conditions were characterized using an Instron Material Testing System. Fracture surfaces were analyzed to understand the failure mechanisms of the nanocomposites.

\section{Materials and methods}

\section{Specimens for tensile}

\section{and compressive tests}

Nanophase titania/PLGA composites

for mechanical tests

PLGA (poly-lactide-co-glycolide or poly-lactic-co-glycolic acid) pellets (50/50 $\mathrm{wt} \%$ poly[DL-lactide/glycolide]; molecular weight: 100,000-120,000 g/mol; intrinsic viscosity: 66-80 $\mathrm{cm}^{3} / \mathrm{g}$; polydispersity: 1.8 ; density: $1.34 \mathrm{~g} / \mathrm{cm}^{3}$; glass transition temperature Tg: $45-50^{\circ} \mathrm{C}$ ) from Polysciences Inc
(Warrington, PA, USA) were used in this study. Nanophase titania powder $\left(\right.$ Nanotek $^{\circledR}$ ) from Nanophase Technologies Corporation (Romeoville, IL, USA) was used as one of the ceramic components in the polymer composites. The purity of the titania powder was $99.5+\%$, the particle size was $32 \mathrm{~nm}$ which was calculated from BET adsorption measurements, the particle morphology was nearly spherical according to TEM images, and the crystalline phase was $80 \%$ anatase $/ 20 \%$ rutile. ${ }^{8,21}$ Bulk and true densities of this titania powder were $0.25 \mathrm{~g} / \mathrm{cm}^{3}$ and $3.96 \mathrm{~g} / \mathrm{cm}^{3}$, respectively.

PLGA was first dissolved in chloroform (Sigma-Aldrich) at $50^{\circ} \mathrm{C}$ and titania nanoparticles were added into the PLGA solution to produce a 30/70 ceramic/polymer weight ratio in the nanocomposites. The nanocomposite mixture was then processed using a Misonix 3000 sonicator (Misonix Inc, Farmingdale, NY, USA) with its microtip immersed in the mixture. The dispersion status of the final composites was controlled by sonication power. The output power of $3 \mathrm{~W}$ and $9 \mathrm{~W}$ were used to obtain agglomerated and dispersed specimens, respectively. The Misonix 3000 sonicator permits the application of ultrasonic energy to suspensions on a pulsed basis. In this study, the pulse width was set at $50 \%$ of the duty cycle out of a 1 second cycle time. This intermittent operation permitted high intensity sonication while avoiding heat buildup in the processed suspensions. After sonication for $10 \mathrm{~min}$, the composite suspension was immediately cast into a mold that was designed for dog-bone shaped tensile specimens or a mold for compressive specimens, evaporated in air at room temperature for 24 hours and dried in an air vacuum chamber at room temperature for 48 hours. According to the titania dispersion states in the polymer, these nano-titania/PLGA composites (PTC) were termed as PTCa (a=agglomerated) and PTCd ( $\mathrm{d}=$ dispersed). PLGA was used as a control and was prepared by the solvent-casting technique described
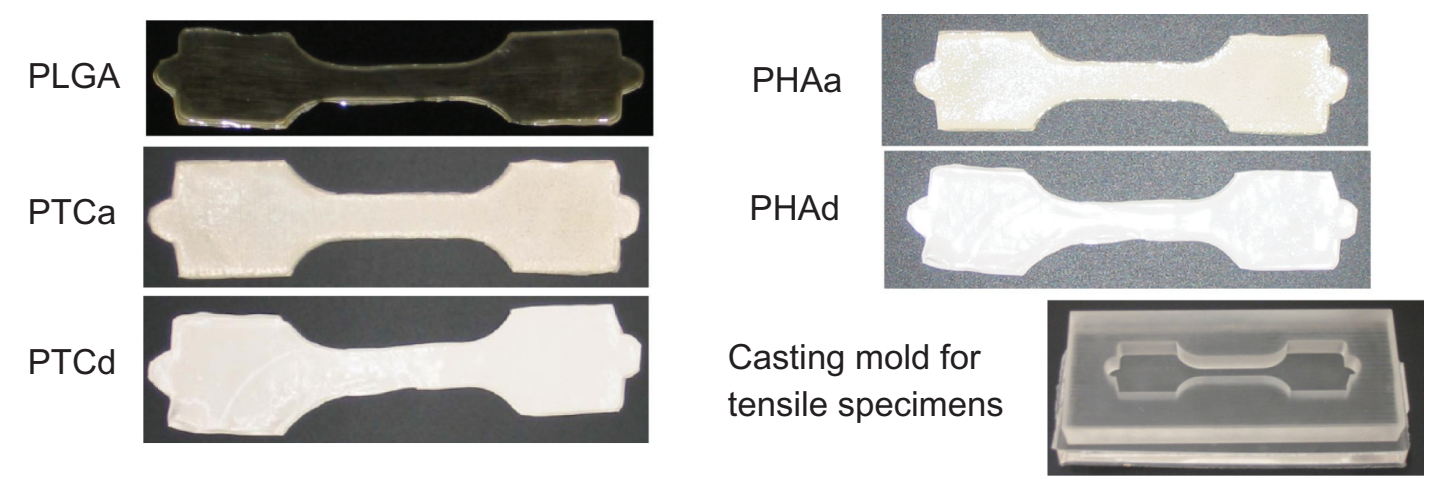

Figure I The mold-cast tensile specimens of PLGA, agglomerated nano-titania in PLGA composites (PTCa), well-dispersed nano-titania in PLGA composites (PTCd), agglomerated nano-HA in PLGA composites (PHAa), well-dispersed nano-HA in PLGA composites (PHAd) and the casting mold for tensile specimens. The tensile specimen gage length $\times$ width $\times$ thickness $=25 \times 10 \times 0.5 \mathrm{~mm}$. The depth of the casting mold was designed as $10 \mathrm{~mm}$. 
above except that no ceramics were added. These mold-cast tensile specimens had the same dimensions (Figure 1). The gage length was $25 \mathrm{~mm}$, the gage width was $10 \mathrm{~mm}$, and the thickness was $0.5 \mathrm{~mm}$. The compressive specimens had a circular shape. The gage diameter of the compressive specimens was $10 \mathrm{~mm}$ and the thickness was $0.5 \mathrm{~mm}$.

\section{Nanophase HA/PLGA composites for mechanical tests}

Nanophase HA was synthesized using a wet chemistry precipitation method by mixing solutions of calcium nitrate and ammonium phosphate in an alkaline $\mathrm{pH}$ solution. ${ }^{22}$ Specifically, a $1 \mathrm{M}$ calcium nitrate solution and a $0.6 \mathrm{M}$ ammonium phosphate solution were prepared by dissolving their respective powders in deionized (DI) water separately. The produced ammonium phosphate solution was mixed with DI water that was adjusted to a $\mathrm{pH}$ of 10 by ammonium hydroxide. The pre-made $1 \mathrm{M}$ calcium nitrate solution was then added into the mixture of ammonium phosphate and ammonium hydroxide at a rate of $3.6 \mathrm{~mL} / \mathrm{min}$. Precipitation occurred as soon as the calcium nitrate was added. Chemically, the HA precipitation occurred through the reaction: ${ }^{1}$

$$
\begin{aligned}
& 10 \mathrm{Ca}\left(\mathrm{NO}_{3}\right)_{2}+6\left(\mathrm{NH}_{4}\right)_{2} \mathrm{HPO}_{4}+8 \mathrm{NH}_{4} \mathrm{OH} \\
& =\mathrm{Ca}_{10}\left(\mathrm{PO}_{4}\right)_{6}(\mathrm{OH})_{2}+6 \mathrm{H}_{2} \mathrm{O}+20 \mathrm{NH}_{4} \mathrm{NO}_{3}
\end{aligned}
$$

Precipitation continued for 24 hours at room temperature with constant stirring. The supernatant was collected, centrifuged (Eppendorf centrifuge, Model $5810 \mathrm{R}$ ) to reduce $75 \%$ of the solution volume and placed into a $125 \mathrm{~mL}$ Teflon liner (Parr Instrument). The Teflon liner was sealed tightly in a Parr acid digestion bomb (Parr Instrument) and treated hydrothermally at $200^{\circ} \mathrm{C}$ for 20 hours to obtain nanocrystalline HA. The hydrothermal treatment demonstrated a great advantage to prepare a stoichiometric, ultrafine HA powder with a homogeneous shape and size distribution due to higher applied pressures than the atmosphere. ${ }^{23,24}$ After the hydrothermal treatment, nano-HA particles were rinsed with DI water and dried in an oven at $80^{\circ} \mathrm{C}$ for 12 hours. The synthesized HA nanoparticles were thoroughly characterized for their size and shape using FESEM and crystalline phase using X-Ray Diffraction (XRD).

The HA nanoparticles were then dispersed into the PLGA to produce a 30/70 ceramic/polymer weight ratio in the nanocomposites using similar procedures previously described for nano-titania/PLGA composites. The sonication time was kept constant at $10 \mathrm{~min}$. The dispersion status of the nanocomposites was controlled by the sonication powers: $3 \mathrm{~W}$ and $9 \mathrm{~W}$ to obtain agglomerated and dispersed specimens, respectively.
These nano-HA/PLGA composites (PHA) were termed PHAa ( $\mathrm{a}=$ agglomerated) and PHAd $(\mathrm{d}=$ dispersed $)$ according to their nano-HA dispersion states. PLGA was used as a control and was prepared by the solvent-casting technique previously described. The tensile specimen gage length was $25 \mathrm{~mm}$, the gage width was $10 \mathrm{~mm}$, and the thickness was $0.5 \mathrm{~mm}$ (Figure 1). The compressive specimens were prepared similarly and had the same dimensions as the PTC.

\section{Design of casting molds for tensile specimens}

The casting molds for tensile specimens were designed based on the requirements of ASTM (American Society for Testing and Materials) standards D638, D882, D3039, and ISO (International Organization for Standardization) standard $37 .^{25-28}$ Figure 1 shows an example of the casting molds used for preparing tensile specimens.

\section{Characterization of materials before mechanical tests}

Surface properties of the titania/PLGA nanocomposites and HA/PLGA nanocomposites were characterized before mechanical tests using a Field Emission Scanning Electron Microscope (FESEM, LEO 1530) at a $3 \mathrm{kV}$ accelerating voltage. SEM images were used to determine the differences in topography and the surface area occupied by the nanoparticles. The surface area occupied by the nanoparticles was highlighted in the SEM images and measured using the ImageJ software. Before SEM imaging, the nanocomposites and PLGA were sputter-coated with a thin layer of goldpalladium, using a Hummer I Sputter Coater (Technics) in a $100 \mathrm{mTorr}$ vacuum argon environment for $3 \mathrm{~min}$ at $10 \mathrm{~mA}$ of current.

\section{Mechanical tests: tensile and compressive tests}

All composites and PLGA were subjected to tensile and compressive tests using an Instron 5882 Mechanical Testing System. A $50 \mathrm{kN}$ load cell was used to measure the load. All samples were pulled at a constant crosshead speed until failure. The extension and compression rate were fixed at $10 \mathrm{~mm} / \mathrm{min}$. Load/displacement curves were obtained using a LabTech software program. The tensile stress-strain curves were calculated from the load-displacement data from tensile tests. The stress was the load divided by cross-section area of tensile specimens. The strain was the extension divided by the gage length of tensile specimens. The tensile modulus, tensile 
strength at yield, ultimate tensile strength (UTS), elongation at yield and elongation at break were calculated from the stress-strain curves according to the established equations. ${ }^{29}$ The compressive modulus was calculated similarly based on compressive tests.

\section{Fracture analysis after tensile tests}

After tensile tests, fracture surfaces, and cross-sections of the titania/PLGA nanocomposites and PLGA were examined using a Field Emission Scanning Electron Microscope (FESEM, LEO 1530) at a $3 \mathrm{kV}$ accelerating voltage. In order to observe fracture cross-sections, specimens were mounted on specially designed $45^{\circ} / 90^{\circ}$ holders. The nanocomposites and PLGA were sputter-coated with a thin layer of goldpalladium before SEM imaging, using a Hummer I Sputter Coater (Technics) in a 100 mTorr vacuum argon environment for $3 \mathrm{~min}$ with $10 \mathrm{~mA}$ of current.

\section{Statistical analyses}

All mechanical tests were repeated three times (three specimens each time) for each type of specimen. Numerical data were analyzed using standard analysis of variance (ANOVA) techniques and standard pair-wised comparison tests; statistical significance was considered at $P<0.05$.

\section{Results \\ Material characterization before mechanical tests Nanophase titania/PLGA composites before mechanical tests}

Scanning electron micrographs suggested that the distribution of nano-titania particles was much different in the PTCa and PTCd samples although both of them had the same weight percentage of titania (that is, $30 \mathrm{wt} \%$ ) in PLGA, as shown in Figure 2. Specifically, there were less titania particles on the top surface of PTCa than PTCd because the ceramic agglomerates larger than $100 \mathrm{~nm}$ descended faster than the solvent evaporation rate according to the established Stoke's Equation. The amount of surface area occupied by titania increased on the top surface of PTCd (10.1\%, Figure $2 d$ ) compared with PTCa (5.7\%, Figure $2 b)$ because the solvent evaporation was much faster than the sedimentation of the well-dispersed titania particles less than $100 \mathrm{~nm}$. Moreover, for the PTCa, the top surface was much different from the bottom surface, which indicated differences in the distribution of the nano-titania agglomerates. More agglomerates were concentrated on the bottom side of the PTCa non-uniformly. For the PTCd, however, there was no significant difference between the top and bottom surfaces and, thus, the distribution of nano-titania in PLGA was more uniform.

\section{Nanophase HA/PLGA composites before mechanical tests}

Nanophase HA synthesized by the aforementioned wet chemistry method demonstrated a relative uniform particle size, as shown in Figure 3a. The SEM images were analyzed using the Image J software and the results showed that the nano-HA had an average particle size of $36 \mathrm{~nm}$. A more detailed analysis on the nanocrystalline HA has been published previously. ${ }^{30}$

Scanning electron micrographs suggested that the distribution of nano-HA particles was much different in the PHAa (Figure 3b,c) and PHAd (Figure 3d,e) samples although both of them had the same weight percentage of HA (that is, $30 \mathrm{wt} \%$ ) in PLGA. Compared with PTC, a similar microstructural trend was observed for PHA. The amount of surface area occupied by HA increased on the top surface of PHAd (11.2\%, Figure 3d) compared with PHAa (7.1\%, Figure $3 \mathrm{~b}$ ) because the solvent evaporation was much faster than the sedimentation of well-dispersed HA nanoparticles smaller than $100 \mathrm{~nm}$ according to the Stoke's Equation calculation. For the PHAa, the top surface appeared much different from the bottom surface, which suggested the non-uniform distribution of nano-HA agglomerates. More agglomerates were concentrated on the bottom side of PHAa. For the PHAd, however, there was no significant difference between the top and bottom surfaces and the distribution of nano-HA in PLGA composites appeared more uniform.

\section{Mechanical properties \\ Mechanical properties of nanophase titania/PLGA composites}

These nanophase titania/PLGA composites enhanced mechanical strength compared with the pure polymer control according to the tensile and compressive test results.

A typical tensile stress-strain curve obtained in the study is shown in Figure 4a. The tensile moduli were calculated from the stress-strain curves and illustrated in Figure 4b. The tensile modulus of the PTCd was about 2 times greater than the PTCa and the tensile modulus of the PTCa was about 3 times greater than the PLGA. Tensile strength at yield, UTS, elongation at yield and elongation at fracture were calculated from the stress-strain curves and illustrated in Figure 4(c-e). PTCd had a greater elastic modulus, tensile strength at 

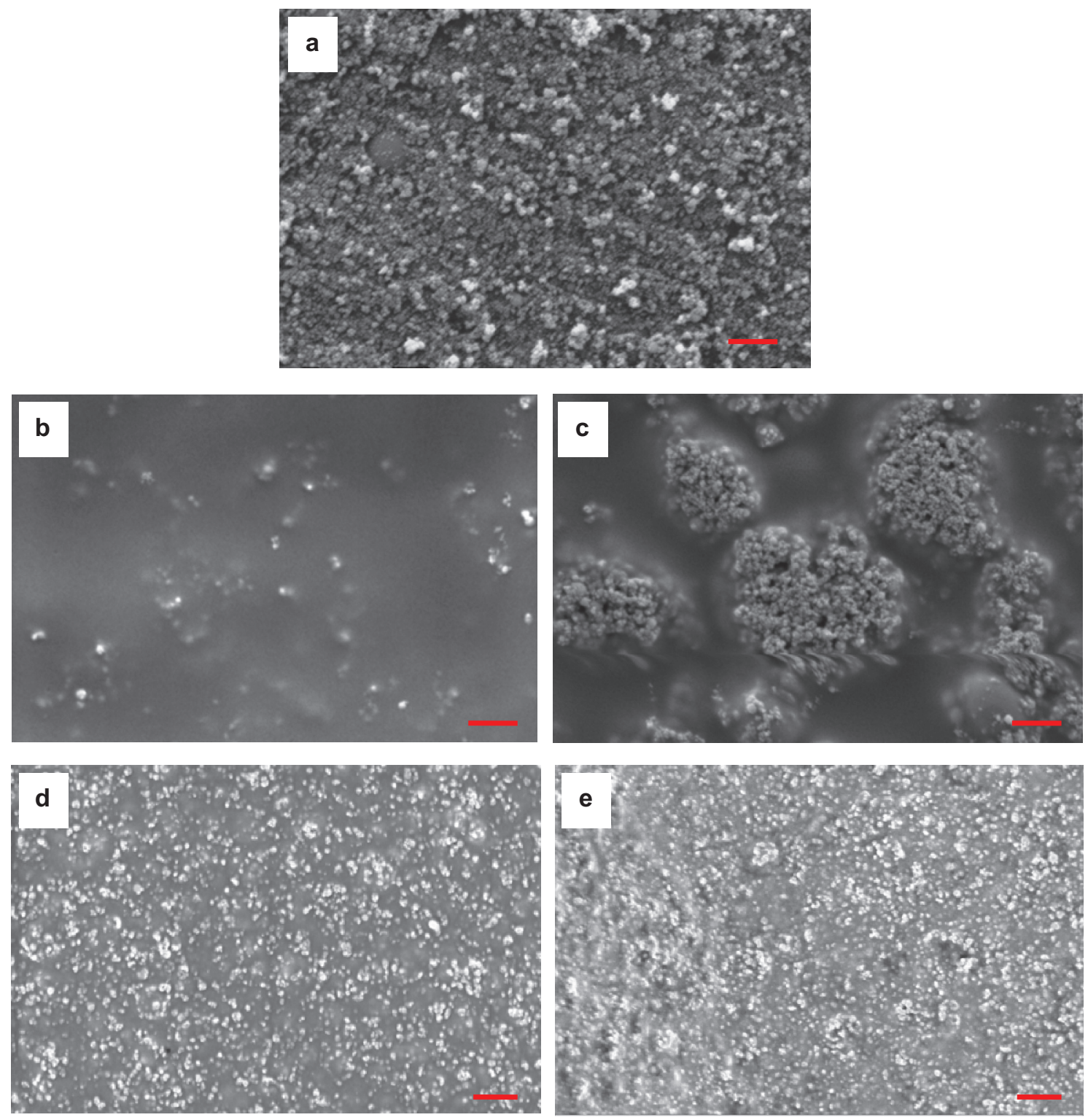

Figure 2 SEM micrographs of nano-titania and nano-titania/PLGA composites: (a) nano-titania, (b,c) PTCa (the agglomerated nano-titania in PLGA composites), (d,e) PTCd (the well-dispersed nano-titania in PLGA composites). (b,d) the top surface, (c,e) the bottom surface. Magnification bars: I $\mu \mathrm{m}$.

yield, and UTS than PTCa and PLGA, while PTCd had less elongation at yield and elongation at break than PTCa and PLGA. The compressive moduli were calculated from the compressive test data and are illustrated in Figure 4f. The compressive modulus of the PTCd was about 2 times greater than the PTCa and the compressive modulus of the PTCa was about 2 times greater than the PLGA.

\section{Mechanical properties of nanophase HA/PLGA composites}

According to the results of tensile and compressive tests, these nanophase HA/PLGA composites demonstrated better mechanical properties than the polymer control.
The tensile stress-strain curves are shown in Figure 5. The tensile moduli, tensile strength at yield, UTS, elongation at yield, and elongation at break were calculated from the stress-strain curves and illustrated in Figure 6(a-d). PHAa and PHAd had a greater elastic modulus, tensile strength at yield and UTS than the PLGA, while PHAa and PHAd had less elongation at yield and elongation at break than the PLGA. It is speculated that, at the microstructural level, the volume of the ductile PLGA phase may be confined by the surrounding brittle nano-HA phase, which may restrict the local deformation under stress, thus impairing the elongation at yield and at break. The compressive moduli were calculated and plotted in Figure 6e. In comparison to natural 

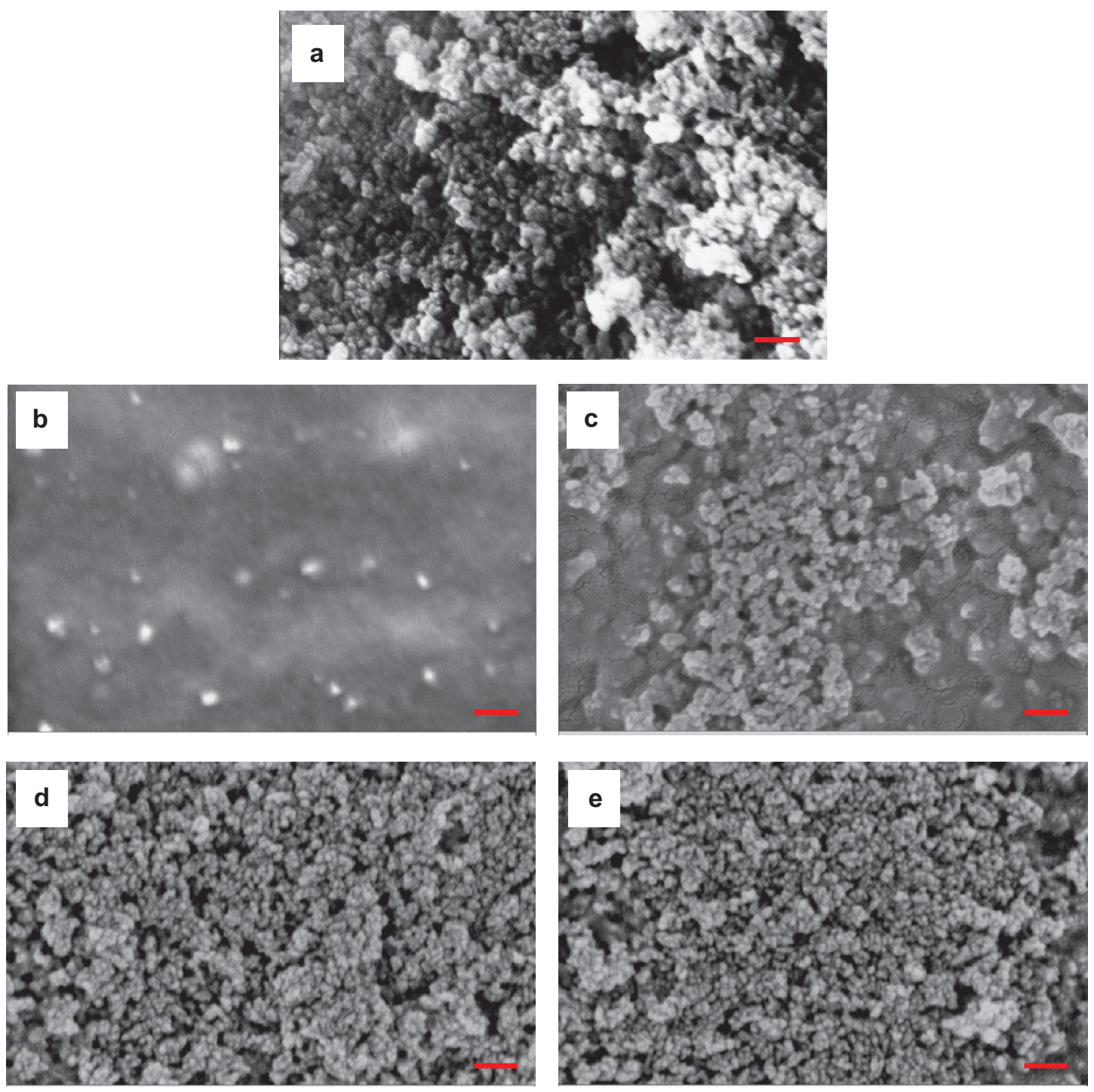

Figure 3 a SEM micrograph of particulate nano-HA synthesized by the wet chemistry method. (b,e) SEM micrographs of nano-HA/PLGA composites: (b,c) PHAa (the agglomerated nano-HA in PLGA composites); (d,e) PHAd (the well-dispersed nano-HA in PLGA composites). (b,d) the top surface, (c,e) the bottom surface. Original magnification: 100 kX. Magnification bars: $200 \mathrm{~nm}$.

bone, the compressive moduli of the PHAa and PHAd were greater and closer to low-density cancellous bone ( 10 MPa) than the PLGA, although further improvement will still be needed to match the mechanical properties of high-density compact bone ( 10 GPa). $)^{31,32}$

\section{Fracture analysis}

The stress-strain behaviors were different between nanotitania/PLGA composites, nano-HA/PLGA composites, and single-phase PLGA. The stress-strain relationship for the nanophase ceramic/PLGA composites demonstrated an initial linear and following nonlinear deformation until fracture. The differences in tensile behaviors clearly influenced the fracture appearance of the nanocomposites even at the macroscopic level (image not shown). This difference in fracture surfaces clearly demonstrated that variations in the ceramic phases (nano-titania or nano-HA), their size and shape, their dispersion states in the polymer matrix, and their interactions with the matrix influenced the fracture behavior of the composites and altered the mechanical performance of the composites.

The site of fracture for the tensile specimens was visualized in Figures $7-11$ to understand the different fracture mechanisms of the materials of interest to this study. Figure 7 shows the representative microscopic appearance of the PLGA fracture surfaces after tensile tests. The river-like bands appeared in Figure 7(a,c,d) were termed as 'sliver streaks'. These silver streaks were very different from microcracks that appeared in Figure 7(b,d) and nanopores that appeared in Figure 7(e,f) due to their unique characteristics. 


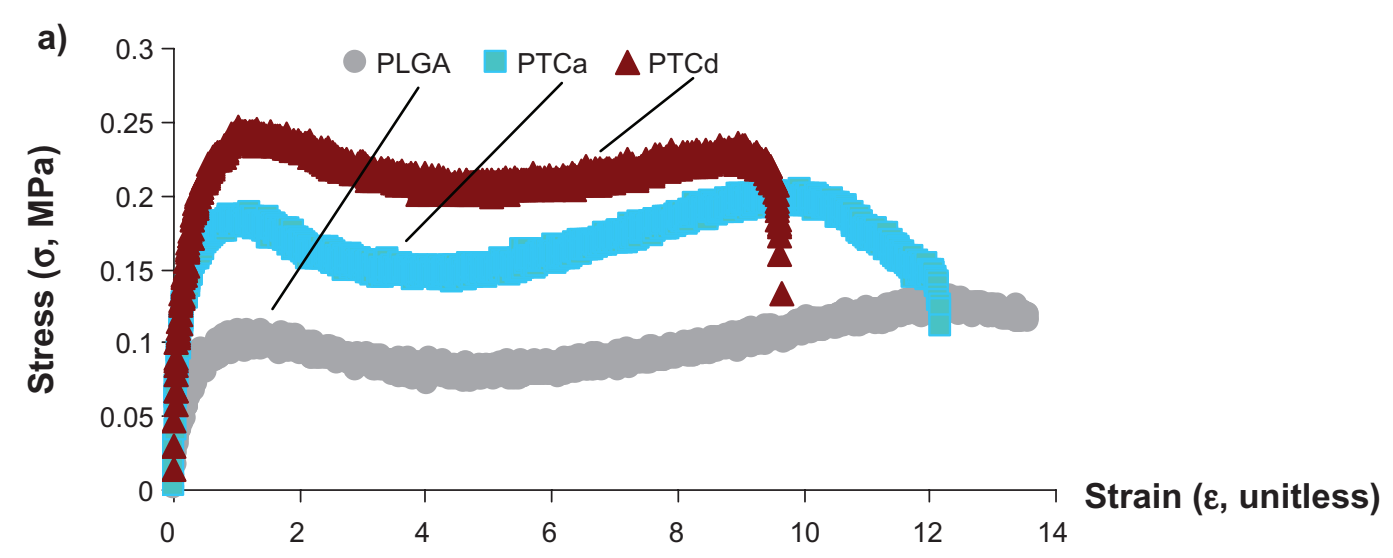

b)
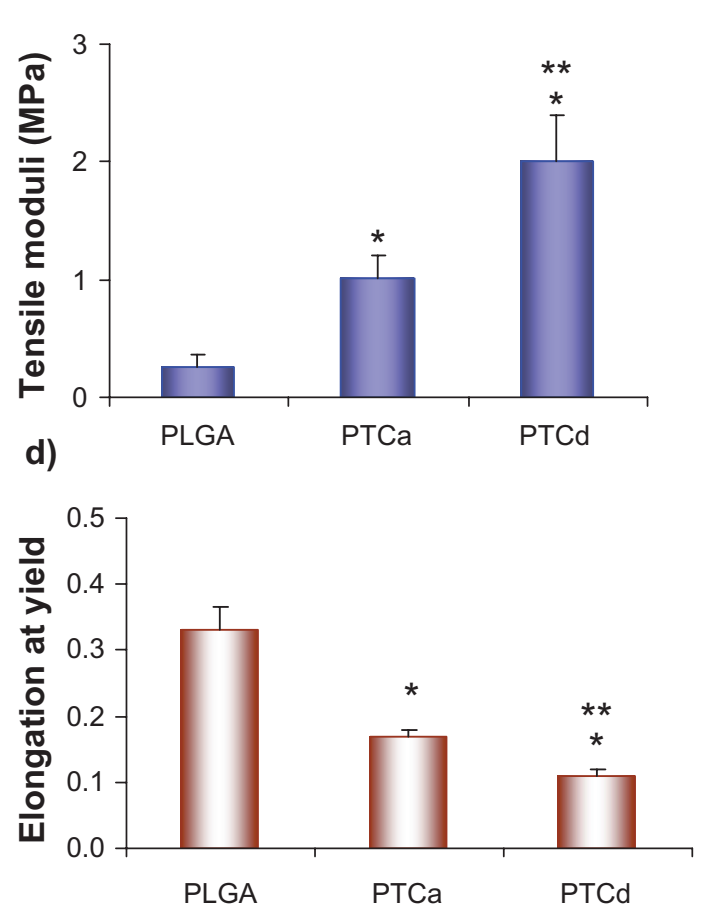

c)

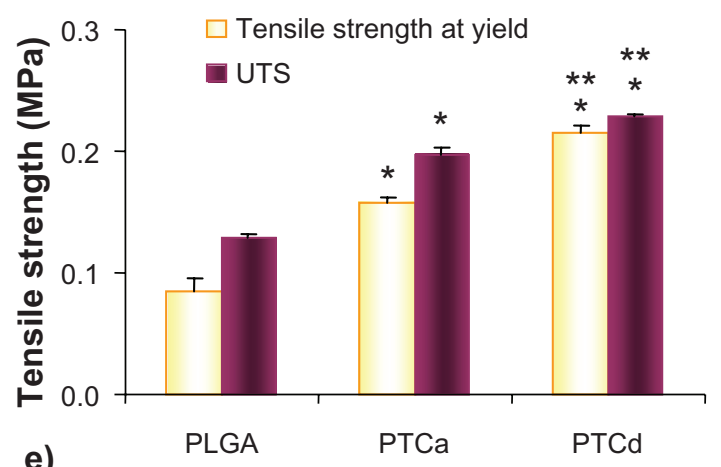

e)

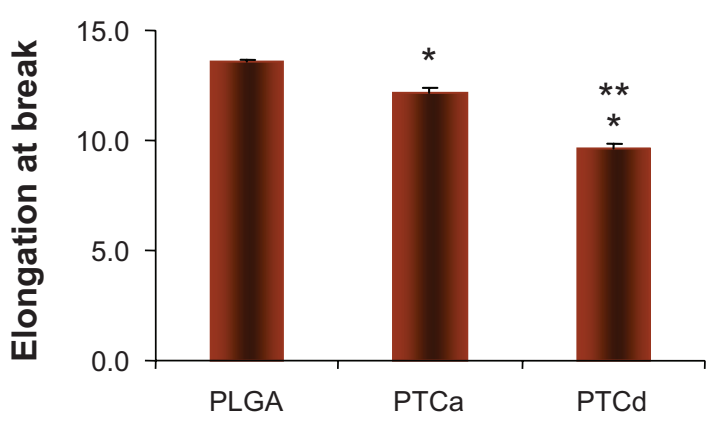

f)

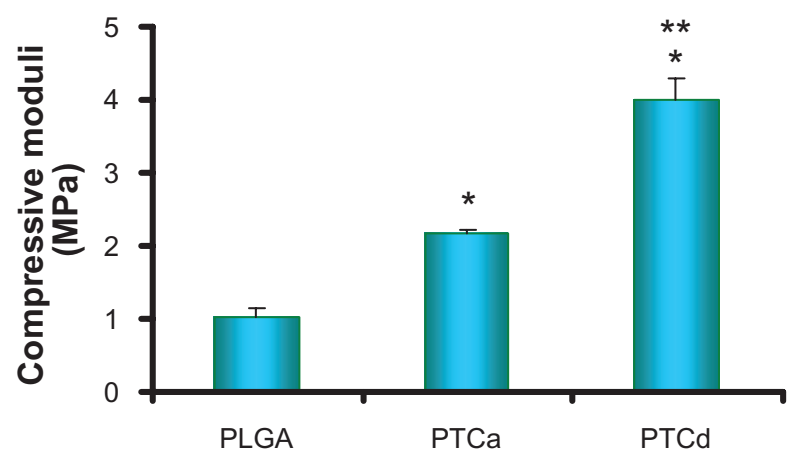

Figure 4 (a) The typical tensile stress-strain curves of PLGA, PTCa (the agglomerated nano-titania in PLGA composites) and PTCd (the well-dispersed nano-titania in PLGA composites) that were calculated from the load-extension data of tensile tests. (b) The tensile moduli of PLGA, PTCa and PTCd. (c) The tensile strength at yield and the ultimate tensile strength (UTS) of PLGA, PTCa and PTCd. (d) The elongation (unitless) at yield and (e) the elongation at break of PLGA, PTCa and PTCd. (f) The compressive moduli of PLGA, PTCa and PTCd.Values are mean \pm SEM; $n=3 ; * p<0.05$ compared with PLGA; and ** $p<0.05$ compared with PTCa. 


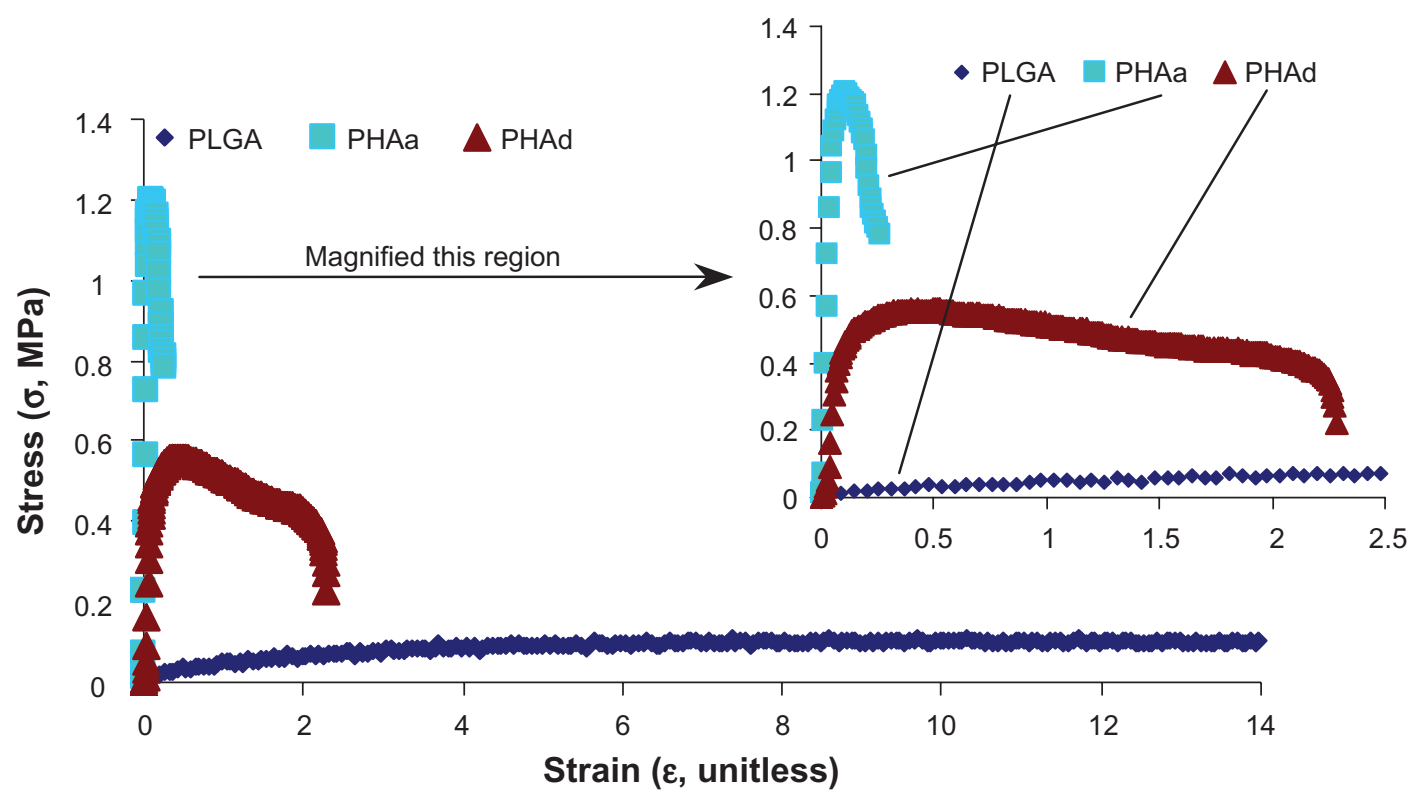

Figure 5 The typical tensile stress-strain curves of PLGA, PHAa (the agglomerated nano-HA in PLGA composites) and PHAd (the well-dispersed nano-HA in PLGA composites) that were calculated from the load-extension data of tensile tests.

First, the silver streaks contained $30-50$ vol\% of polymers while there were no polymers observed inside the microcracks or the nanopores. Second, these silver streaks maintained certain strength compared with the microcracks and the nanopores. Third, the silver streaks were reversible while the microcracks and nanopores were irreversible. The silver streaks could be reduced or even removed under compressive stress or heat (temperatures above $\mathrm{T}_{\mathrm{g}}$ ). Moreover, the density and refractive index of the silver streak region decreased compared with the original non-deformed polymers due to void formation. When the volume gain induced by the extension along the direction of the load could not compensate for the volume loss due to the contraction along the direction perpendicular to the load, the silver streaks and voids would begin to form. The orientation of the silver streaks was perpendicular to the direction of load, as shown in Figure 7.

Figures 8 and 9 show microscopic fractures on the PTCa (agglomerated nano-titania/PLGA composites) after tensile tests. Figure 8a shows the fracture cross-section of the PTCa. Figure $8(b, c, d)$ shows the top surfaces of PTCa near the fracture cross-section. Figure 9 shows the bottom surfaces of the PTCa near the fracture cross-sections. The de-bonding of the ceramic phase from the polymer matrix was evident for PTCa, as shown in Figure 9(b,c,d). The silver streaks were observed on the top surface in Figure $8 b$. The microcracks and nanopores were observed on the top surfaces in Figure 8d. Crack initiation and propagation were observed in Figure 8c.
Figures 10 and 11 shows microscopic fractures on the PTCd (well-dispersed nano-titania/PLGA composites) after tensile tests. Figure 10a shows the fracture cross-section of the PTCd. Figure 10(b,c,d) shows the top surfaces of PTCd near the fracture cross-section. Figure 11 shows the bottom surfaces of the PTCd near the fracture cross-sections. The de-bonding of the ceramic phase from the polymer matrix was also observed for PTCd, as shown in Figures 10(b,c) and 11(b,c,d). The silver streaks, however, were not observed on the top surface of PTCd. The microcracks and nanopores were present on the top surfaces in Figures 10(b,d). Crack initiation, propagation, and branching were observed in Figures 10d and 11a.

Microcracks and nanopores were also observed on both PTCa and PTCd. However, the amount of microcracks and the size of microcracks were very different on PTCa and PTCd. As observed, there were smaller and less amounts of microcracks on PTCd than on PTCa. Cracks propagated along the interface of the ceramic and the polymer matrix. There were also instances when the crack did not initiate at the interface, but at the polymer phase (Figure 8d). In these rare cases, it was speculated that the high local stress concentrations were created due to the poor distribution of ceramic particles.

\section{Discussion}

Many factors contribute to the mechanical properties of nano-ceramic/polymer composites, including size and shape of ceramic nanoparticles, ceramic/polymer phase 
a)

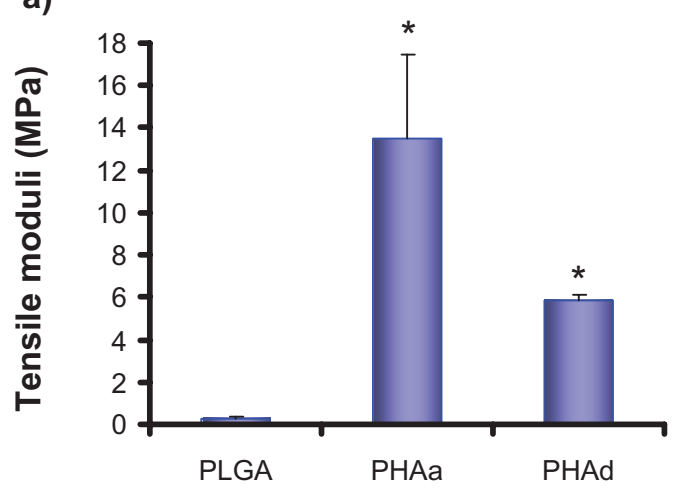

c)

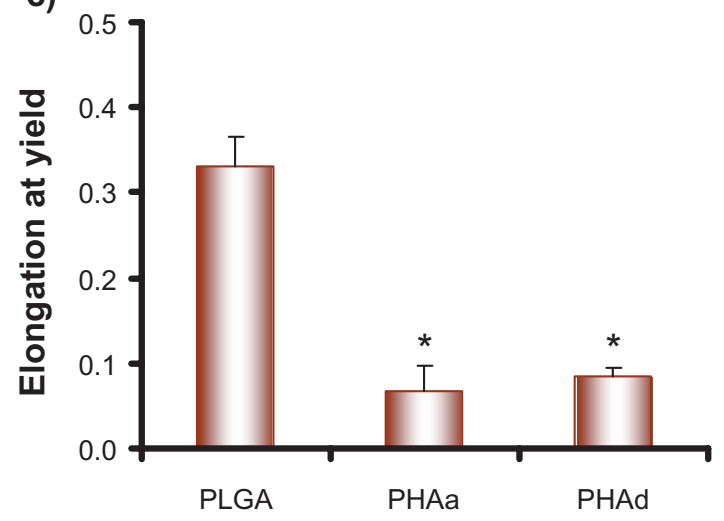

b)

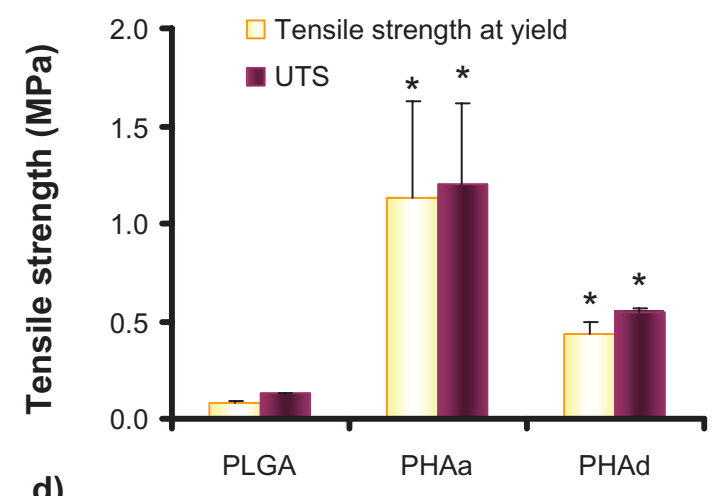

d)

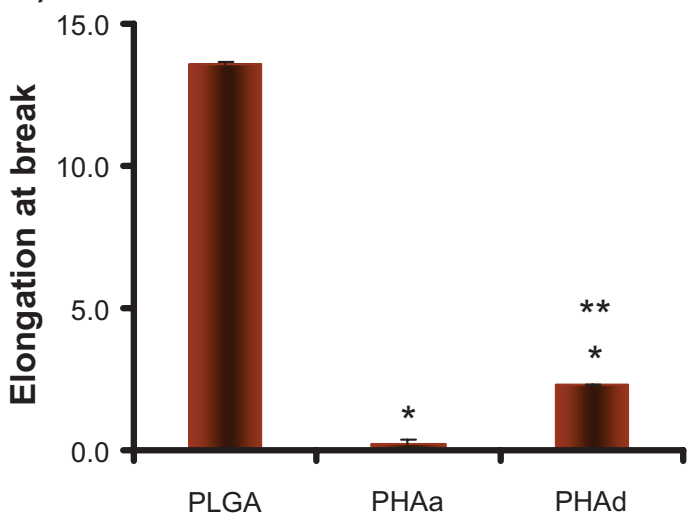

e)

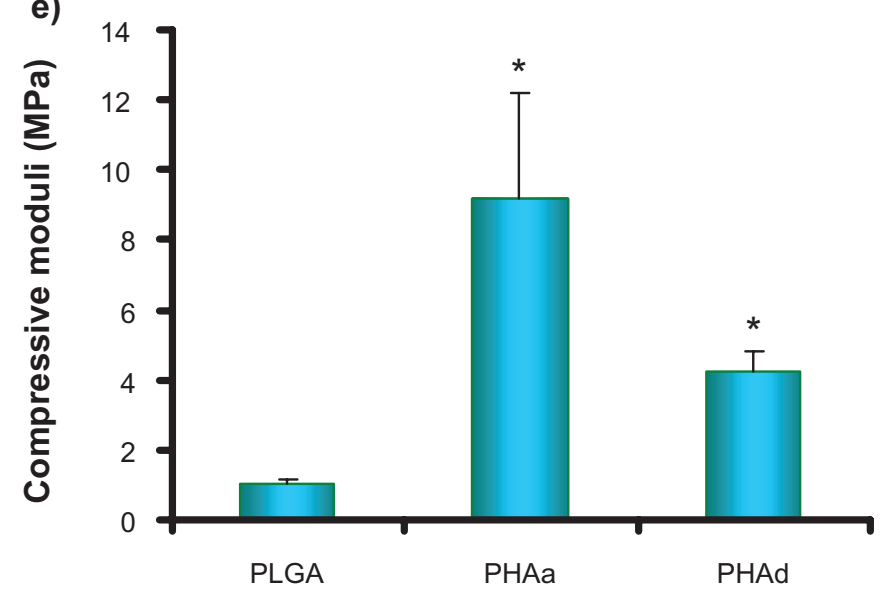

Figure 6 (a) The tensile moduli of PLGA, PHAa (the agglomerated nano-HA in PLGA composites) and PHAd (the well-dispersed nano-HA in PLGA composites). (b) The tensile strength at yield and the ultimate tensile strength (UTS) of PLGA, PHAa and PHAd. (c) The elongation (unitless) at yield and (d) the elongation at break of PLGA, PHAa and PHAd. (e) The compressive moduli of PLGA, PHAa, and PHAd.Values are mean \pm SEM; $n=3 ;{ }^{*} p<0.05$ compared with PLGA; and ** $p<0.05$ compared with PHAa.

composition, dispersion of nanoparticles, physical or chemical interactions between the ceramic and polymer phase, and inherent properties of the polymer matrix. It is intriguing to speculate why well-dispersed nanoceramics in polymer composites improved the mechanical properties of the composites and how the fracture behavior of nanocomposites could be modified through controlling the dispersion. The interfacial PLGA-ceramic structure played a critical role in determining the mechanical properties of the composites.
For example, it was reported that a better bonding between the polymer matrix and the reinforcing phase resulted in a higher elastic modulus and a higher strength. ${ }^{33,34}$ Since the predominant feature of the nanoparticles lies in their ultrafine dimension, a large fraction of filler atoms can reside at the PLGA-ceramic interface which can lead to a stronger interfacial interaction, but only if the nanoparticles are well-dispersed at the nanoscale in the surrounding polymer matrix. Nanocomposites with a greater number of smaller 


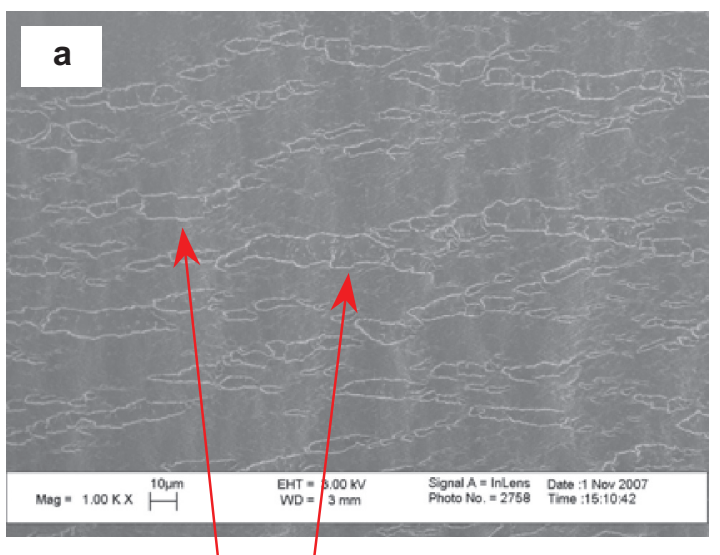

\section{Silver streak}

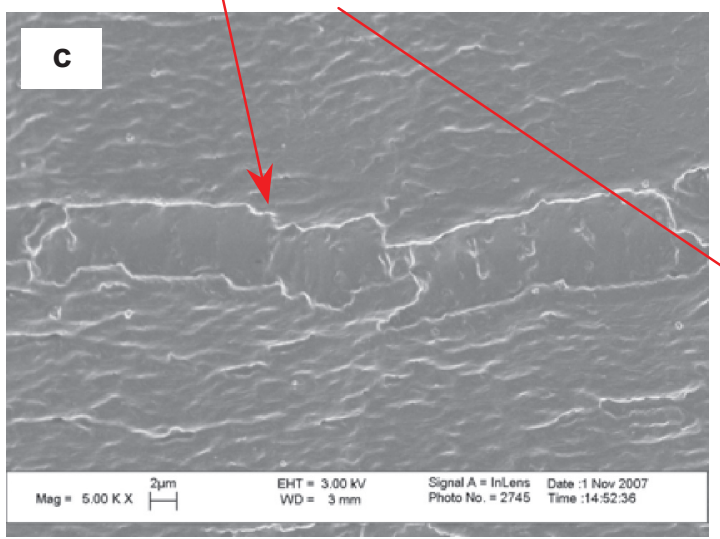

Nanopore

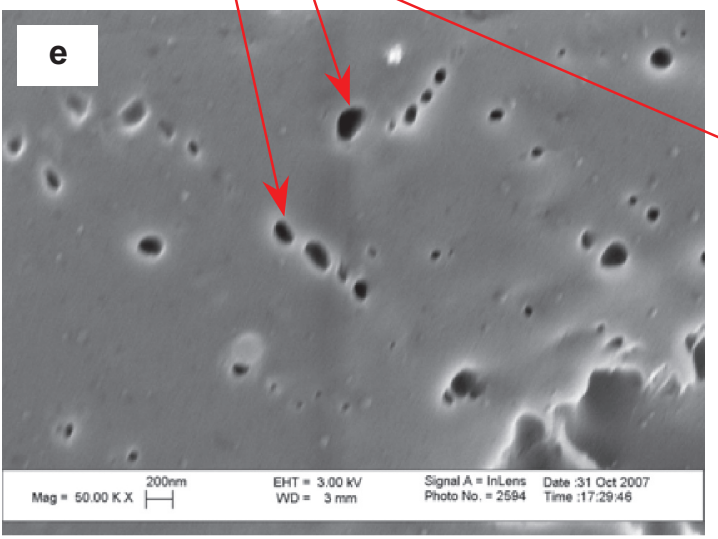

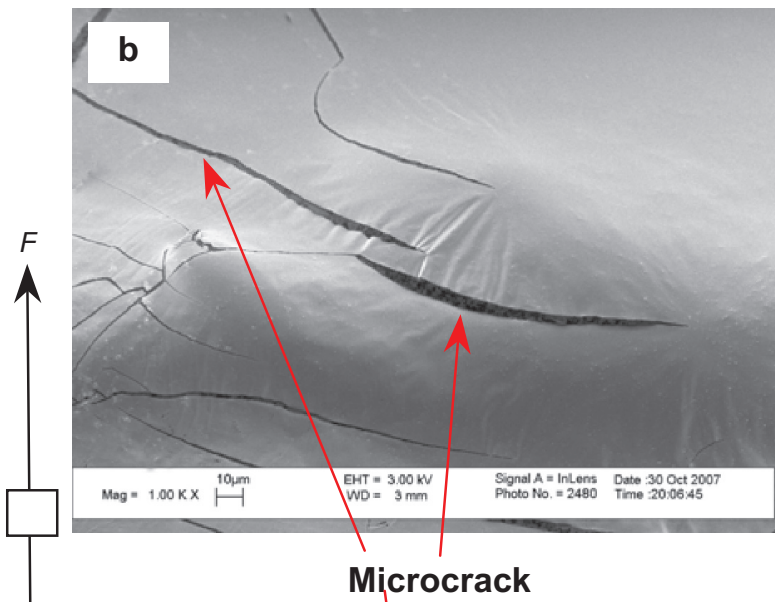

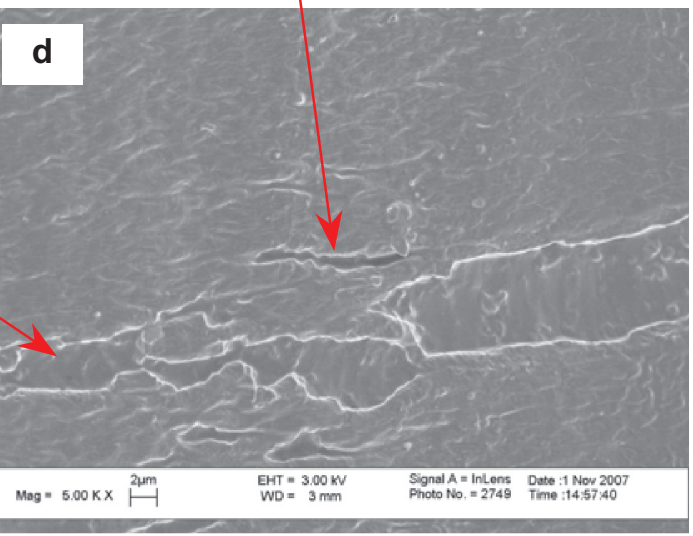

Figure 7 Microscopic fracture appearances of PLGA after tensile tests. Original magnifications are I kX for (a,b), 5 kX for (c,d) and 50 kX for (e,f). Magnification bars are $10 \mu \mathrm{m}$ for $(\mathbf{a}, \mathbf{b}), 2 \mu \mathrm{m}$ for $(\mathbf{c}, \mathbf{d})$ and $200 \mathrm{~nm}$ for $(\mathbf{e}, \mathbf{f})$. F shows the direction of the load.

interfaces could be expected to provide unusual properties, and the shortcomings induced by the heterogeneity of conventional (or micron) particle filled composites would also be decreased or even eliminated.

Scientifically, it is a great challenge to transfer the desirable mechanical properties (such as Young's modulus (E), compressive strength, and hardness) of nanoscale ceramics into macroscale ceramic/polymer nanocomposites, although single-phase nanoceramics possess exceptional compressive strength, stiffness, and hardness. Mechanical properties of nanoparticle-filled polymer composites have been significantly improved compared with conventional larger particle-filled polymer composites, but they are still far below the predicted theoretical values which were determined based on the assumption that nanoscale building blocks were individually dispersed in the matrix, except in the case of very low volume fractions of the reinforcing phase. ${ }^{35-38}$ Non-ideal mechanical properties of ceramic/polymer nanocomposites 

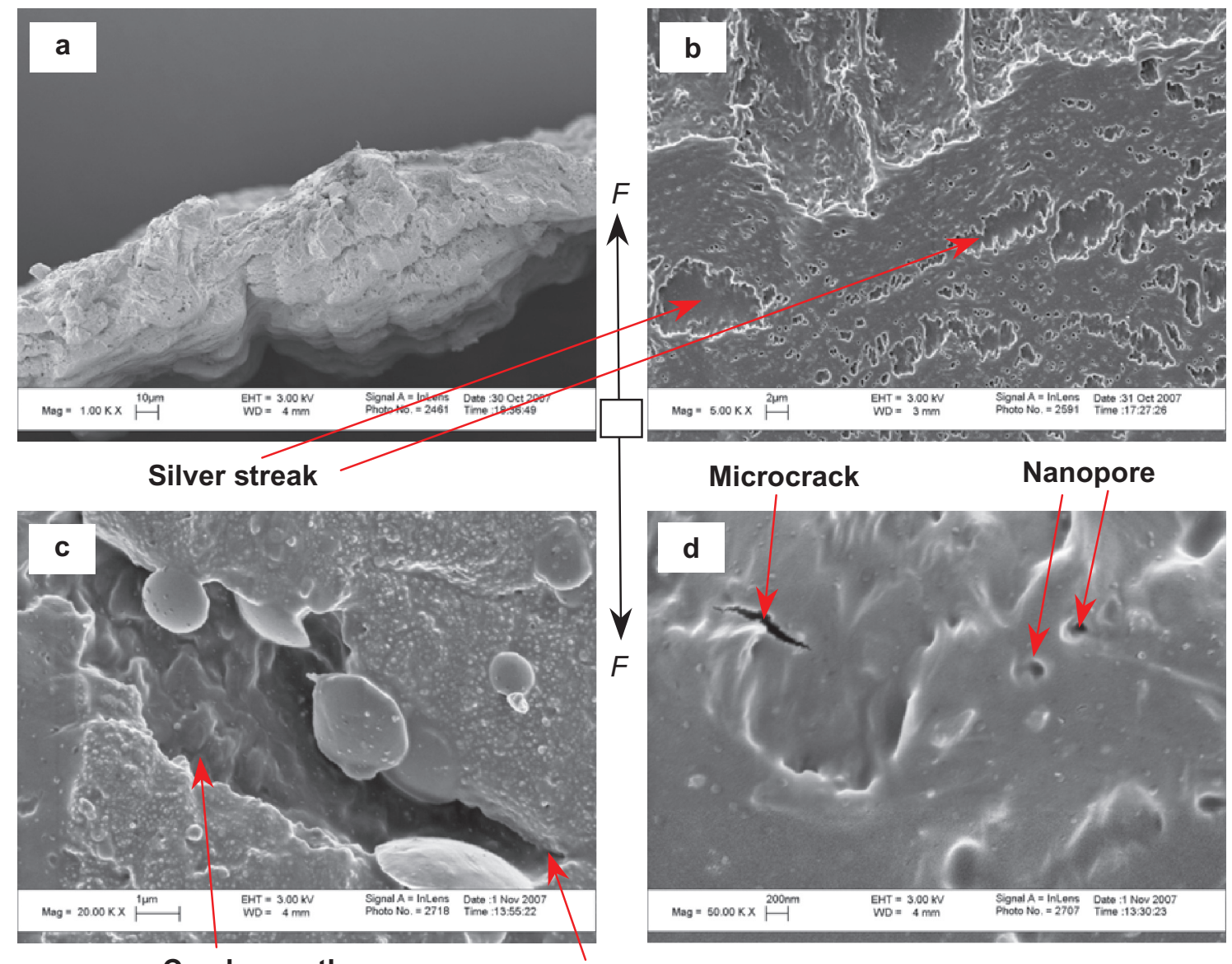

\section{Crack growth}

\section{Crack tip}

Figure 8 Microscopic fracture appearances of PTCa (agglomerated nano-titania in PLGA composites) after tensile tests. The fracture cross-section is shown in (a). The top surfaces of PTCa near the fracture cross-section are shown in (b,c,d). Original magnifications are I kX for (a), 5 kX for (b), 20 kX for c and 50 kX for (d). Magnification bars are $10 \mu \mathrm{m}$ for (a), $2 \mu \mathrm{m}$ for (b), I $\mu \mathrm{m}$ for (c) and $200 \mathrm{~nm}$ for (d). F shows the direction of the load.

are largely related to the difficulties in dispersing large volume fractions of the reinforcing nanoceramics in polymer composites. As mentioned, nanoparticles have a strong tendency to agglomerate in the composites, especially when they take up more than $2 \mathrm{wt} \%$ of the composites. In addition, it is important to control an effective load transfer from the polymeric matrix to the nanoscale ceramic components (that is, particle/matrix bonding) and understand the respective mechanical properties of the particles and matrix as well as the interactions of the two constituents at the nanoscale.

For loading-bearing orthopedic applications, it is important to produce a nanocomposite with mechanical properties closer to their theoretical values. Approaches include controlling spatial distribution and orientation of nanoparticles in a polymer matrix at the nanoscale, and retaining this order at the macroscale. For example, Podsiadlo et al assembled a homogeneous, optically transparent clay (montmorillonite, MTM)/polymer (poly[vinyl alcohol], PVA) nanocomposite with planar orientation of alumosilicate nanosheets using a bottom-up layer-by-layer (LBL) assembly process. ${ }^{35}$ The tensile strength (UTS) of these multilayer MTM/PVA composites reached $400 \pm 40 \mathrm{MPa}$ and the Young's modulus reached $106 \pm 11 \mathrm{GPa}$, one order of magnitude greater than that of PVA. The nanoscale dimension of the inorganic MTM phase and the nearly perfect orientation and fine dispersion of the MTM nanoplatelets may contribute to the exceptional mechanical properties. ${ }^{35}$ A highly effective load transfer between nanosheets and the polymer was, thus, achieved by combining highly ordered nanoscale building blocks with dense covalent and hydrogen bonding that stiffened the polymer chains. The greater mechanical properties of PVA/MTM nanocomposites resulted from several mechanisms at the nanoscale. The degree of structural organization (afforded by the LBL process) of the clay platelets in the composite maximizes the number of polymer/ MTM interactions and constrains the polymer-chain motion, which resulted in a highly efficient load transfer between the polymer phase and the stiff MTM platelets.

In this study, nano-HA/PLGA composites demonstrated different mechanical properties (Figures 5 and 6 ) from nano- 

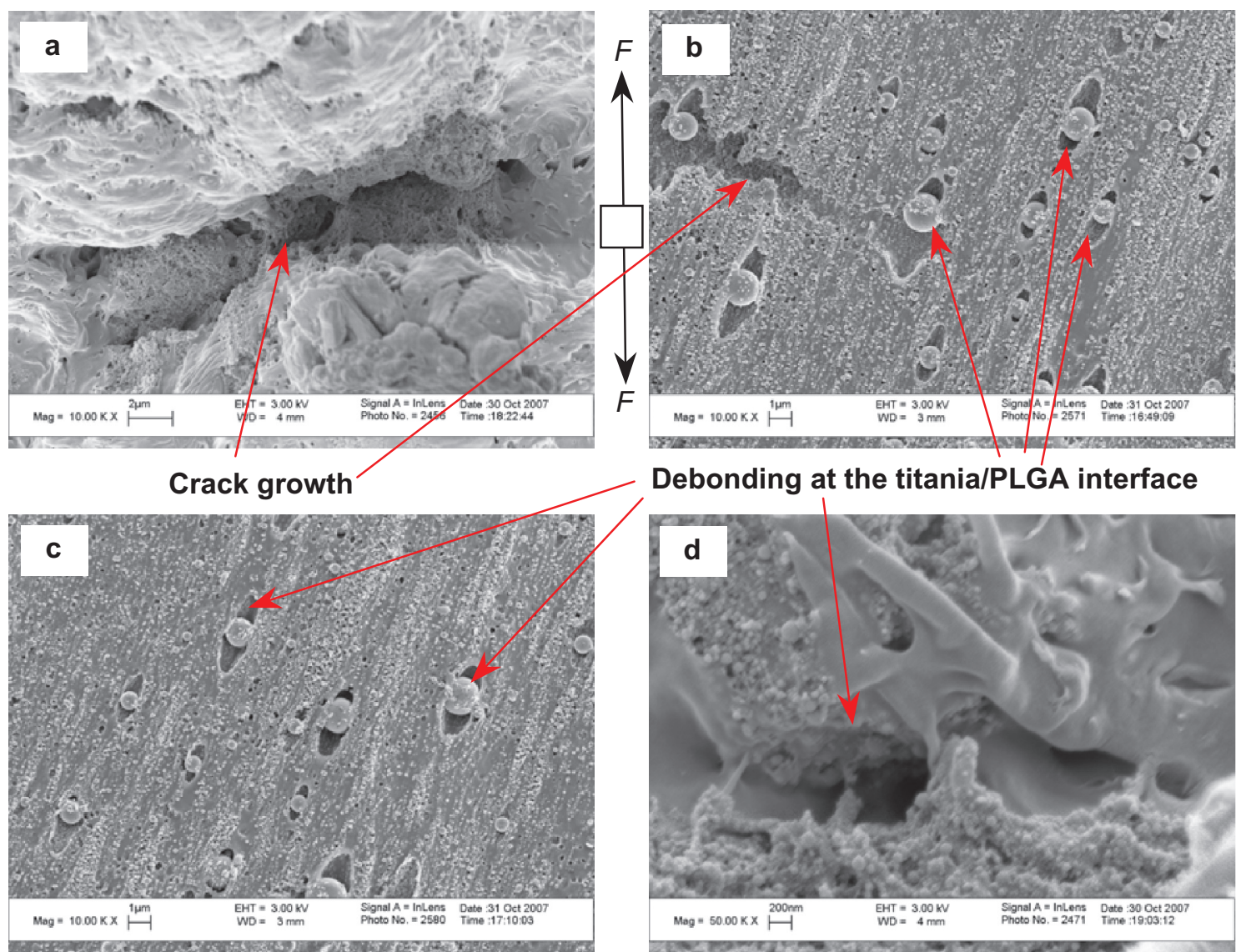

Figure 9 Microscopic fracture appearances of PTCa (agglomerated nano-titania in PLGA composites) after tensile tests. The bottom surfaces of the PTCa near the fracture cross-sections. Original magnifications are $10 \mathrm{kX}$ for $(\mathbf{a}, \mathbf{b}, \mathbf{c})$ and $50 \mathrm{kX}$ for $(\mathbf{d})$. Magnification bars are $2 \mu \mathrm{m}$ for $(\mathbf{a}), \mathrm{I} \mu \mathrm{m}$ for $(\mathbf{b}, \mathbf{c})$ and $200 \mathrm{~nm}$ for $(\mathbf{d})$. $F$ shows the direction of the load.

titania/PLGA composites (Figure 4). The potential explanation is believed to mainly lie in the different chemistry and geometry of nano-HA versus nano-titana particles. It is speculated that the interactions between nano-HA and PLGA would be very different from the interactions between nano-titania and PLGA due to the different particle surface chemistry. Moreover, different particle geometry of nano-HA and titania also plays an important role in the particle distribution and interactions with the polymer, thus responsible for the differences in their mechanical properties. The more uniform the nanoparticle dispersion in the polymer and the stronger interaction between the nanoparticles and polymer matrix, the more improved the mechanical properties. One of the approaches to improve dispersion of nanoparticles in a polymer matrix and enhance particle-polymer bonding is surface functionalization of particles. For example, Guo et al functionalized iron oxide $\left(\mathrm{Fe}_{2} \mathrm{O}_{3}\right)$ nanoparticles with a bi-functional coupling agent methacryloxypropyl-trimethoxysilane (MPS) and observed better dispersion of nanoparticles in resin composites and, thus, greater tensile strength as compared to the as-received nanoparticle filled vinyl ester resin nanocomposites. ${ }^{39}$ What features in the functionalized nanoparticle filled composites led to an increase in mechanical properties? It was speculated that well-dispersed nanoparticles were strongly bound with the polymer matrix through the bridging effect of MPS between the nanoparticles and polymer matrix. Therefore, in the vinyl ester resin composites reinforced with MPS-functionalized iron oxide nanoparticles, the stresses can be more easily transferred from the matrix to the particles, thus, decreasing stress concentration. The intimate contact between the particles and the matrix also ensured a reduction in crack propagation.

In order to further match the mechanical properties of ceramic/polymer nanocomposites with natural bone, additional efforts should be made to explore the theories and postulations discussed above to continue to optimize the dispersion of nanoparticles, which is the key to greater mechanical properties.

\section{Conclusions}

The dispersion of ceramic nanoparticles (titania or HA) in PLGA promoted mechanical properties of orthopedic materials as compared to PLGA and agglomerated 

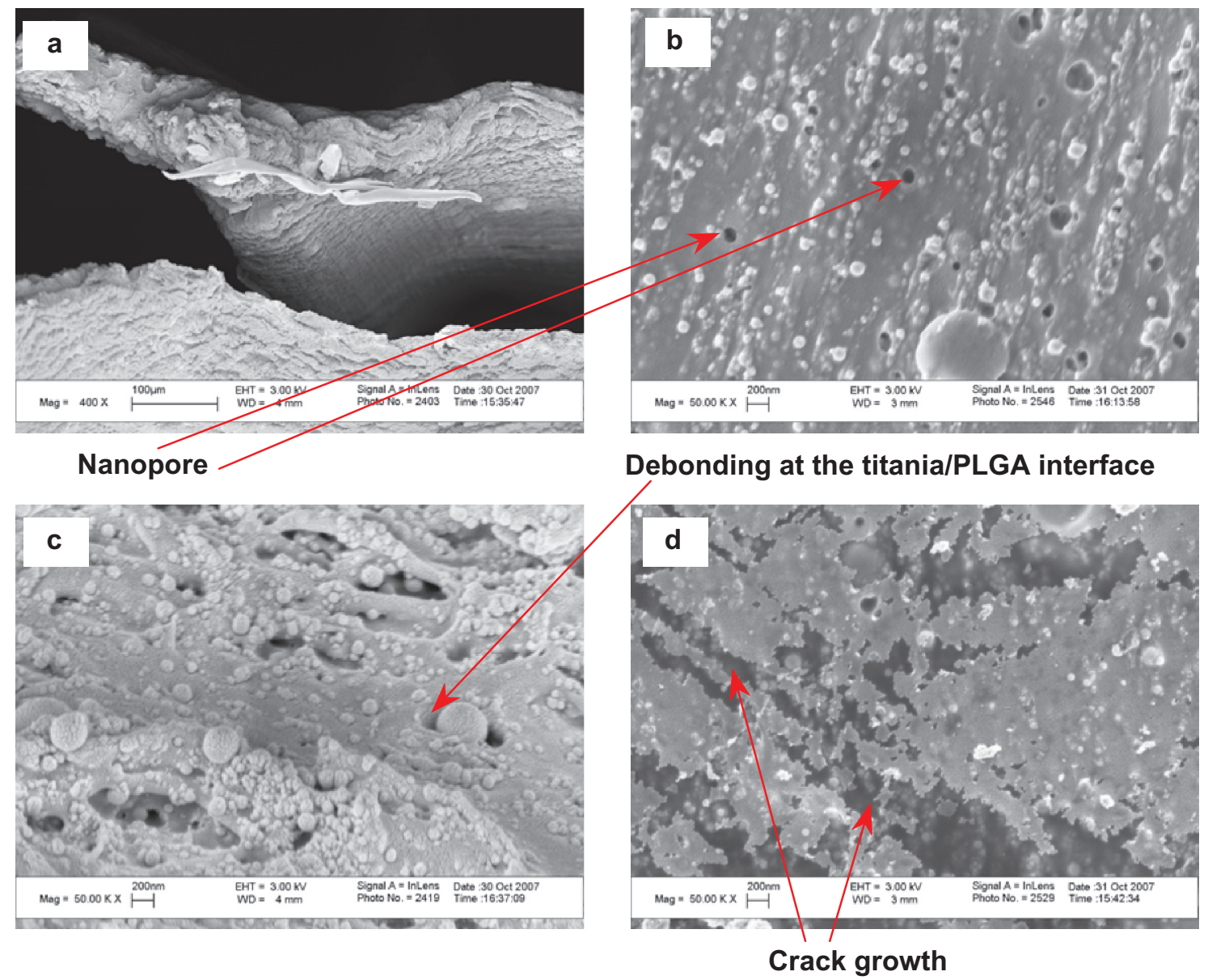

Figure 10 Microscopic fracture appearances of PTCd (well-dispersed nano-titania in PLGA composites) after tensile tests. The fracture cross-section is shown in (a). The top surfaces of PTCd near the fracture cross-section are shown in (b,c,d). Original magnifications are $400 X$ for (a) and $50 \mathrm{kX}$ for (b,c,d). Magnification bars are I00 $\mu \mathrm{m}$ for (a) and $200 \mathrm{~nm}$ for (b,c,d).

ceramic/PLGA composites. For example, well-dispersed nano-titania/PLGA composites improved the tensile modulus, tensile strength at yield, ultimate tensile strength and compressive modulus as compared with PLGA and the more agglomerated nano-titania/PLGA composites. As expected, nano-HA/PLGA nanocomposites also demonstrated a greater tensile modulus, tensile strength, and compressive modulus than the PLGA. Although the well-dispersed nano-HA/PLGA composites (PHAd) had a slightly lower tensile modulus, tensile strength, and compressive modulus compared with PHAa, PHAd had much better ductility (greater elongation at yield and greater elongation at break) than PHAa.

In conclusion, when collectively considering these results, the combination of the ductile PLGA with a strong, biocompatible, and well-dispersed nanoceramic phase can be very promising for customizing mechanical properties of the nextgeneration orthopedic biomaterials. Coupled with prior studies demonstrating greater osteoblast functions, ${ }^{40}$ the combination of PLGA with nanoceramics may provide better candidate materials for more effective orthopedic/dental applications, from both a biological and mechanical perspective.

\section{Acknowledgments}

The authors would like to thank the NSF for a Nanoscale Exploratory Research (NER) grant and Christopher Bull for his assistance with the Instron Mechanical Testing System.

\section{Disclosures}

No conflicts of interest were declared in relation to this paper.

\section{References}

1. Traykova T, Aparicio C, Ginebra MP, Planell JA. Bioceramics as nanomaterials. Nanomedicine. 2006;1(1):91-106.

2. Boccaccini AR, Maquet V. Bioresorbable and bioactive polymer/ bioglass ${ }^{\circledR}$ composites with tailored pore structure for tissue engineering applications. Composites Sci Technol. 2003;63(16):2417-2429.

3. Hutmacher DW. Scaffolds in tissue engineering bone and cartilage. Biomaterials. 2000;21(24):2529-2543. 
4. Thomson RC, Yaszemski MJ, Powers JM, Mikos AG. Hydroxyapatite fiber reinforced poly $(\alpha$-hydroxy ester) foams for bone regeneration. Biomaterials. 1998;19(21):1935-1943.

5. Marra KG, Szem JW, Kumta PN, DiMilla PA, Weiss LE. In vitro analysis of biodegradable polymer blend/hydroxyapatite composites for bone tissue engineering. J Biomed Mater Res. 1999;47(3):324-335.

6. Kalita S, Finley J, Bose S, Hosick H, Bandyopadhyay A. Development of porous polymer-ceramic composites as bone grafts. Mater Res Soc Symp Proc. 2002;726:91-96.

7. Blaker JJ, Gough JE, Maquet V, Notingher I, Boccaccini AR. In vitro evaluation of novel bioactive composites based on bioglass ${ }^{\circledR}$-filled polylactide foams for bone tissue engineering scaffolds. J Biomed Mater Res A. 2003;67(4):1401-1411.

8. Liu H, Slamovich EB, Webster TJ. Increased osteoblast functions among nanophase titania/poly(lactide-co-glycolide) composites of the highest nanometer surface roughness. J Biomed Mater Res. 2006;78A(4):798-807.

9. Ma PX, Zhang R, Xiao G, Franceschi R. Engineering new bone tissue in vitro on highly porous poly $(\alpha$-hydroxyl acids)/hydroxyapatite composite scaffolds. J Biomed Mater Res. 2001;54(2):284-293.

10. Liu H, Slamovich EB, Webster TJ. Less harmful acidic degradation of poly(lactic-co-glycolic acid) bone tissue engineering scaffolds through titania nanoparticle addition. Int J Nanomed. 2006;1(4):541-545.

11. Zhang R, Ma PX. Degradation behavior of porous poly $(\alpha$-hydroxy acids)/hydroxyapatite composite scaffolds. Polymer Preprints. 2000;41(2):1618-1619.

12. Rho JY, Kuhn-Spearing L, Zioupos P. Mechanical properties and the hierarchical structure of bone. Med Eng Phys. 1998;20(2):92-102.

13. Kasuga T, Ota Y, Nogami M, Abe Y. Preparation and mechanical properties of polylactic acid composites containing hydroxyapatite fibers. Biomaterials. 2001;22(1):19-23

14. Navarro M, Ginebra MP, Planell JA, Zeppetelli S, Ambrosio L. Development and cell response of a new biodegradable composite scaffold for guided bone regeneration. J Mater Sci: Mater Med. 2004;15(4): 419-422.

15. Khan YM, Katti DS, Laurencin CT. Novel polymer-synthesized ceramic composite-based system for bone repair: an in vitro evaluation. J Biomed Mater Res A.2004;69(4):728-737.

16. Wei G, Ma PX. Structure and properties of nano-hydroxyapatite/ polymer composite scaffolds for bone tissue engineering. Biomaterials. 2004;25(19):4749-4757.

17. Chaim R. Plastic deformation in impure nanocrystalline ceramics: a model. Scr Mater. 2001;44( 8-9):1523-1527.

18. Narayan RJ, Kumta PN, Sfeir C, Lee DH, Choi D, Olton D. Nanostructured ceramics in medical devices: applications and prospects. JOMJ Minerals, Metals Mater Soc. 2004;56(10):38-43.

19. McManus AJ, Doremus RH, Siegel RW, Bizios R. Evaluation of cytocompatibility and bending modulus of nanoceramic/polymer composites. J Biomed Mater Res. 2005;72A(1):98-106

20. Liu H, Webster TJ. Ceramic/polymer nanocomposites with tunable drug delivery capability at specific disease site. J Biomed Mater Res. 2009; Sep 23. [Epub ahead of print].

21. Nanophase. http://www.nanophase.com/catalog/ [online] Accessed in December 2003.
22. Sato M, Sambito MA, Aslani A, Kalkhoran NM, Slamovich EB, Webster TJ. Increased osteoblast functions on undoped and yttrium-doped nanocrystalline hydroxyapatite coatings on titanium Biomaterials. 2006;27(11):2358-2369.

23. Ioku K, Yoshimura M. Stoichiometric apatite fine single crystals by hydrothermal synthesis. Phosphorus Res Bull. 1991;1:15-20.

24. Somiya S, Ioku K, Yoshimura M. Hydrothermal synthesis and characterization of fine apatite crystals. Mater Sci Forum. 1988;34-36(1): 371-378.

25. International Organization for Standardization. ISO 37 Rubber, vulcanized or thermoplastic - Determination of tensile stress-strain properties. 2005. Available from: http://www.iso.org/iso/catalogue detail.htm?csnumber=40200. Accessed on March 11, 2010.

26. ASTM International. ASTM D3039/D3039M-08 Standard Test Method for Tensile Properties of Polymer Matrix Composite Materials. 2010. Available from: http://www.astm.org/Standards/D3039.htm. Accessed on March 11, 2010.

27. ASTM International. ASTM D638-08 Standard Test Method for Tensile Properties of Plastics. 2010. Available from: http://www.astm org/Standards/D638.htm. Accessed on March 11, 2010.

28. ASTM International. ASTM D882-09 Standard Test Method for Tensile Properties of Thin Plastic Sheeting. Available from: http://www.astm. org/Standards/D882.htm. Accessed on March 11, 2010.

29. Callister WD. Materials Science and Engineering: An Introduction. 6th Edition. ISBN: 978-0-471-73696-7. John Wiley \& Sons, Inc; 2003. p. 113-152.

30. Balasundaram G, Sato M, Webster TJ. Using hydroxyapatite nanoparticles and decreased crystallinity to promote osteoblast adhesion similar to functionalizing with RGD. Biomaterials. 2006;27(14):2798-2805.

31. Fung YC. Biomechanics: mechanical properties of living tissues. New York: Springer-Verlag, 1993. p. 500-519.

32. Swartz DE, Wittenberg RH, Shea M, White AA III, Hayes WC. Physical and mechanical properties of calf lumbosacral trabecular bone. J Biomech. 1991;24(11):1059-1068.

33. Charvet JL, Cordes JA, Alexander H. Mechanical and fracture behavior of a fiber-reinforced bioabsorbable material for orthopaedic applications. J Mater Sci: Mater Med. 2000;11(2):101-109.

34. Mamiya T, Kagawa Y, Shioji Y, Sato M, Yamamura T. Tensile fracture behavior and strength of surface-Modified SiTiCO fiber SiC-matrix minicomposites fabricated by the PIP process. J Am Ceram Soc. 2000;83(2):433-435.

35. Podsiadlo P, Kaushik AK, Arruda EM, Waas AM, Shim BS, Xu JD, et al. Ultrastrong and stiff layered polymer nanocomposites. Science. 2007;318(5847):80-83.

36. Treacy MMJ, Ebbesen TW, Gibson JM. Exceptionally high Young's modulus observed for individual carbon nanotubes. Nature. 1996;381(6584):678-680.

37. Yu MF, Lourie O, Dyer MJ, Moloni K, Kelly TF, Ruoff RS. Strength and breaking mechanism of multiwalled carbon nanotubes under tensile load. Science. 2000;287(5453):637-640.

38. Mack JJ, Viculis LM, Ali A, Luoh R, Yang GL, Hahn HT, et al. Graphite nanoplatelet reinforcement of electrospun polyacrylonitrile nanofibers. Adv Mater. 2005;17(1):77-80.
International Journal of Nanomedicine

\section{Publish your work in this journal}

The International Journal of Nanomedicine is an international, peerreviewed journal focusing on the application of nanotechnology in diagnostics, therapeutics, and drug delivery systems throughou the biomedical field. This journal is indexed on PubMed Central,

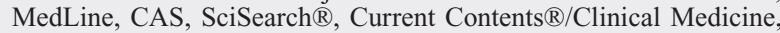

\section{Dovepress}

Journal Citation Reports/Science Edition, EMBase, Scopus and the Elsevier Bibliographic databases. The manuscript management system is completely online and includes a very quick and fair peer-review system, which is all easy to use. Visit http://www.dovepress.com/ testimonials.php to read real quotes from published authors. 